\title{
FLEXURAL BEHAVIOUR OF REINFORCED CEMENT CONCRETE BEAM WRAPPED WITH GFRP SHEET
}

\author{
D.N. Shinde ${ }^{1}$, Pudale Yojana $\mathrm{M}^{2}$, Nair Veena $\mathrm{V}^{3}$ \\ ${ }^{1}$ Associate Professor, Department of Civil Engineering, P.V.P.I.T. Budhgaon, Maharashtra, India \\ ${ }^{2}$ Student, Department of Civil Engineering, P.V.P.I.T. Budhgaon, Maharashtra, India \\ ${ }^{3}$ Student, Department of Civil Engineering, P.V.P.I.T. Budhgaon, Maharashtra, India
}

\begin{abstract}
Existing concrete structures may, for a variety of reasons, be found to perform unsatisfactorily. This could manifest itself by poor performance under service loading, in the form of excessive deflections and cracking, or there could be inadequate ultimate strength. Additionally, revisions in structural design and loading codes may render many structures previously thought to be satisfactory, noncompliant with current provisions. In the present economic climate, rehabilitation of damaged concrete structures to meet the more stringent limits on serviceability and ultimate strength of the current codes, and strengthening of existing concrete structures to carry higher permissible loads, seem to be a more attractive alternative to demolishing and rebuilding. This paper investigates the Flexural behavior of R.C.C. beam wrapped with GFRP Glass Fiber Reinforced Polymer) sheet. A total 8 beams, with (150 $\times 150) \mathrm{mm}$ rectangular cross section and of span $700 \mathrm{~mm}$ were casted and tested. Three main variables namely, strength, ductility and damage level of R.C.C. under reinforced beam and R.C.C. beam weak in flexure were investigated. In first set of four R.C.C. under reinforced beams two were strengthened with GFRP sheet in single layer from tension face which is parallel to beam axis subjected to static loading tested until failure; the remaining two beams were used as a control specimen. In second set of four beams weak in flexure two were strengthened with GFRP sheet tested until failure; the remaining two were used as a control specimen. Comparison has been made between results of two sets.
\end{abstract}

Keywords: Beam, Glass fiber reinforced polymer sheet, Reinforced Cement concrete Beam

\section{INTRODUCTION}

All over the world there are structures intended for living and transportation. The structures are of varying quality and function, but they are all ageing and deteriorating over time. Some of these structures are in such a bad condition that they need to be replaced. There is also a need for upgrading existing structures. Errors can have been made during the design or construction phase so that structures need to be strengthened before it can be fully utilized. New and increased demands from the transportation sector or change of use can also be reasons for upgrading existing structures. A strengthening method that has been increasingly used during the last decade Civil engineering structures are an important element of infrastructure and provide good service to the user they experience distresses on account of reasons and need strengthening to bring them back to their originally intended service mode. If effective methods are used for strengthening it is possible to bring structures back to their originally intended service usages many modern techniques are involved to proper effective strengthening methods.

FRP can be applied to strengthen the beams, columns, and slabs of buildings and bridges. It is possible to increase the strength of structural members even after they have been severely damaged due to loading conditions. In the case of damaged reinforced concrete members, this would first require the repair of the member by removing loose debris and filling in cavities and cracks with mortar or epoxy resin. Once the member is repaired, strengthening can be achieved through the wet hand lay-up process of impregnating the fiber sheets with epoxy resin then applying them to the cleaned and prepared surfaces of the member. [8]

Two techniques are typically adopted for the strengthening of beams, relating to the strength enhancement desired: flexural strengthening or shear strengthening. In many cases it may be necessary to provide both strength enhancements. For the flexural strengthening of a beam, FRP sheets or plates are applied to the tension face of the member (the bottom face for a simply supported member with applied top loading or gravity loading). Principal tensile fibers are oriented in the beam longitudinal axis, similar to its internal flexural steel reinforcement. This increases the beam strength and its stiffness (load required to cause unit deflection), however decreases the deflection capacity and ductility. 


\section{EXPERIMENTAL INVESTIGATION}

\subsection{Specimen Details}

The experimental programme consists of the testing of 8 R.C.C. beam specimens. The beam had a cross-section of $(150 \times 150) \mathrm{mm}$ with an overall length $700 \mathrm{~mm}$. The fig. shows cage of the beam.

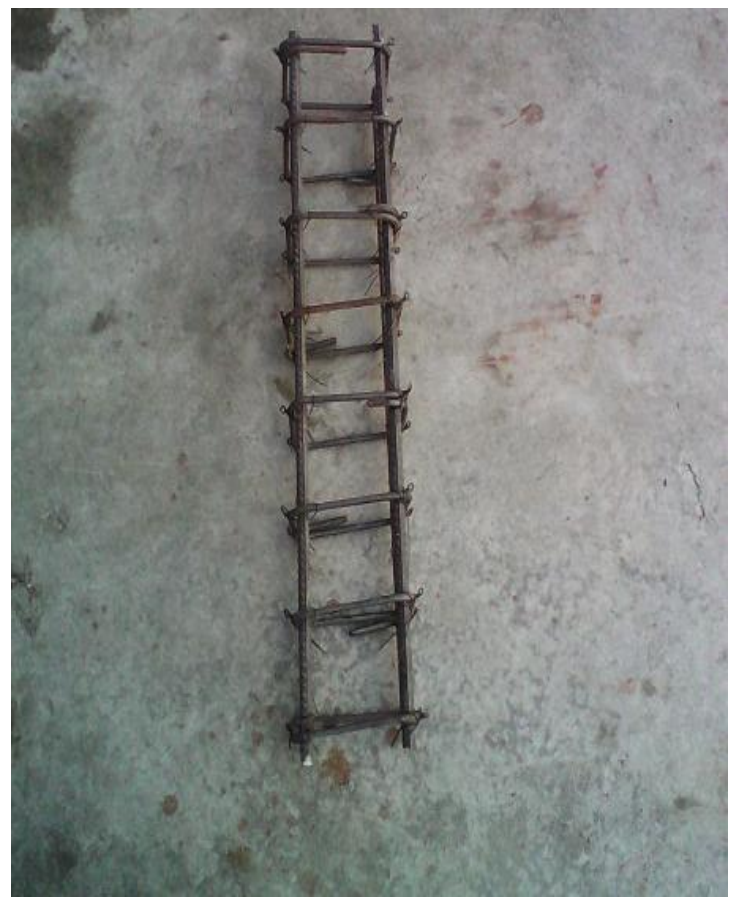

Fig -1: Cage of Beam

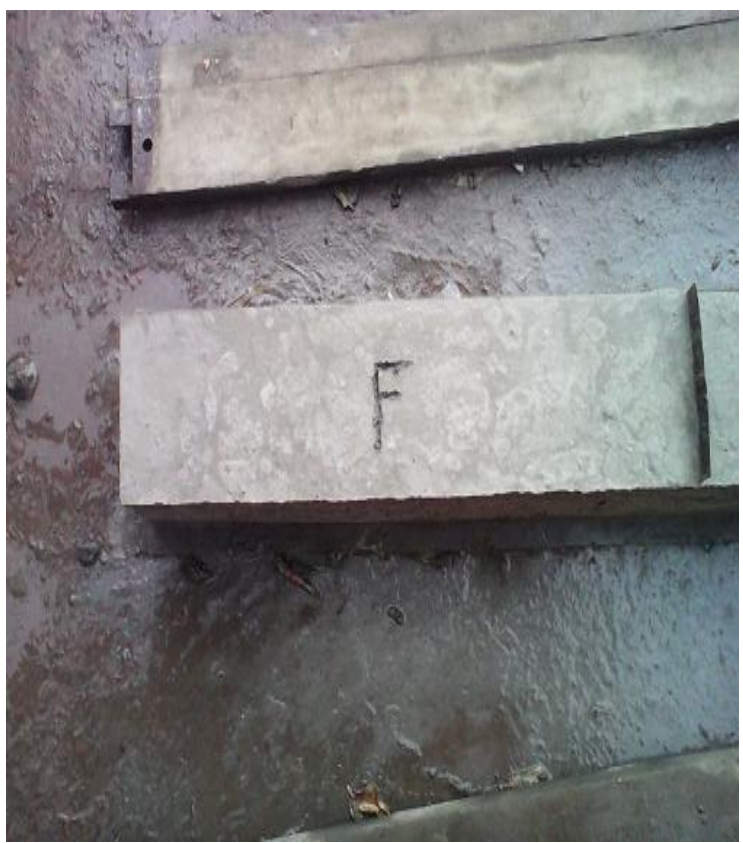

Fig-2: Formwork with beam specimen

\subsection{Reinforcement Details:}

Out of 8 beams 4 were designed as under reinforced, reinforced with 2- $12 \mathrm{~mm}$ diameter bar at bottom, 2-8 $\mathrm{mm}$ diameter bar at top using 6mm dia. Stirrups @ $90 \mathrm{~mm} \mathrm{c/c}$ as shown in fig.2.1 and remaining 4 beams were designed as weak in flexure, reinforced with reduction of $70 \%$ main bottom steel and shear stirrups maintaining same as under reinforced as shown in fig 2.2. They were designed such that failure would be due to flexural in beam during the test, so as to evaluate the contribution of GFRP to the flexural capacity of beam.

All the eight reinforced concrete beam casted and cured for one month. The experimental programme consists of strengthening using glass fiber reinforced polymer. Out of these eight specimen four under reinforced specimen named as RCC1,RCC2,RCCR1,RCCR2 and other four weak in flexure specimen named as WF1,WF2,WFR1,WFR2 before conducting test.
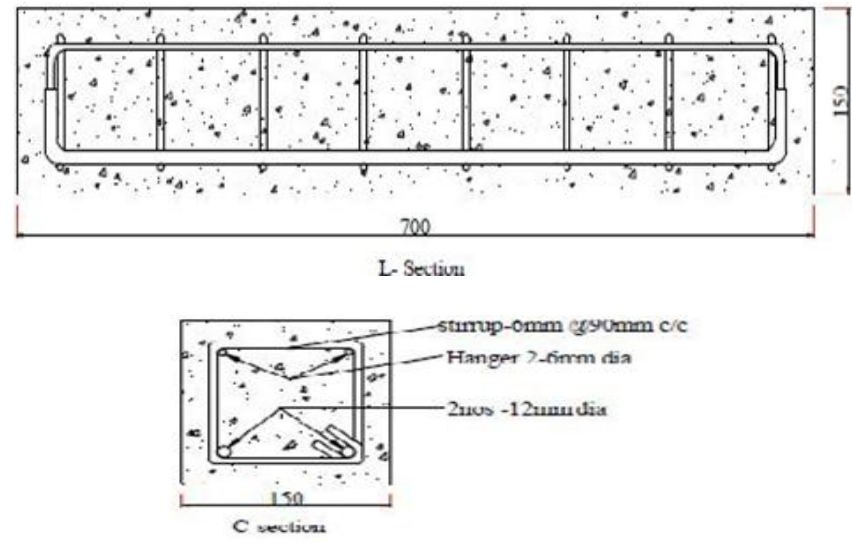

Fig -3: Reinforcement details of R.C.C. balance section as per IS 456:2000
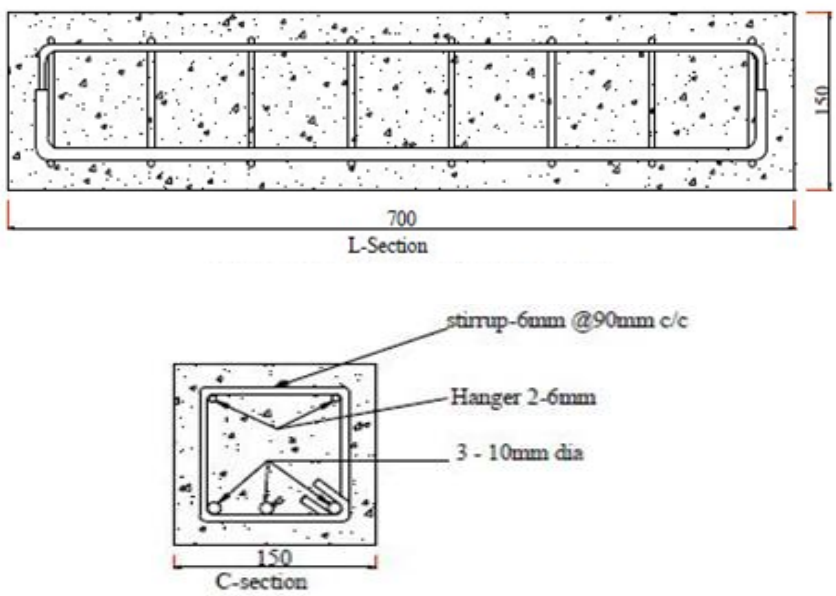

Fig-4: Reinforcement details of R.C.C. beam weak in flexure as per IS 456:2000 


\subsection{Material Properties}

Concrete mix of M30 grade was used for all beams. The proportions in the concrete mix were 1.0 (cement) : 1.0 (sand) : 2.2 (gravel) by weight as per as per 10262:1982. The water/cement ratio was 0.4 and type I Portland cement was used. The average yield stress of main steel bars used in all experiments was $500 \mathrm{MPa}$ and an elastic modulus of $200 \mathrm{GPa}$. GFRP sheet properties given as below:
Weight of fiber
$920 \mathrm{~g} / \mathrm{m}^{2}$
Density of fiber
$2.6 \mathrm{~g} / \mathrm{cc}$
Fiber thickness
Fiber orientation
$0.36 \mathrm{~mm}$
Nominal thickness per layer $0.36 \mathrm{~mm}$
Tensile strength
$3400 \mathrm{~N} / \mathrm{mm}^{2}$
Tensile modulus
$73,000 \mathrm{~N} / \mathrm{mm}^{2}$

\subsection{Casting and Curing}

The mould is arranged properly and placed over a smooth surface. The sides of the mould exposed to concrete were oiled well to prevent the side walls of the mould from absorbing water from concrete and to facilitate easy removal of the specimen. The reinforcement cages were placed in the moulds and cover between cage and form provided was $20 \mathrm{~mm}$. Cement mortar block pieces were used as cover blocks. The concrete contents such as cement, sand, aggregate and water were weighed accurately and mixed. The mixing was done till uniform mix was obtained. The concrete was placed into the mould immediately after mixing and well compacted. The test specimens were remolded at the end of 24 hours of casting. They were marked identifications. They are cured in water for 28 days. After 28 days of curing the specimen was dried in air and white washed.

\subsection{Application Procedure of GFRP Wrapping}

\subsubsection{Surface Preparation (Specimen)}

As per recommendations of retrofitting work to get strengthening of structural elements, Surface preparation is an important task in our experimental work. This task was done with the help of grinding machine (To avoid undulation on surface of specimen), Emery cloth, Carborandum stone (for smooth surface), Blower machine (cleaning the dust).

\subsubsection{Preparation of Retrofit Test Specimens:}

The CFRP sheets were bonded to the tension face of the specimens after 28 days of casting. Before applying the epoxy, the concrete surface was smoothened and cleaned to insure a good bond between the epoxy glue and the concrete surface. The epoxy was hand-mixed and hand-applied at an approximate thickness of about $1 \mathrm{~mm}$. The bond thickness was not specifically controlled, but the excess epoxy was squeezed out along the edges of the sheet, assuming complete epoxy coverage. More details about the methodology utilized to fix the CFRP sheets to the different beams are discussed.

\subsection{Test Set-up:}

The specimen were tested by using Universal testing machine by keeping the beam in horizontal position with two loading system of $20 \mathrm{~cm}$ internal loading distance and hinge at distance of $5 \mathrm{~cm}$ from the end support. The sustained loading was applied from top of the beams until we could identify the hair cracks and we have noted down the first cracking loads, further the loading is continued until we get the ultimate load that the steel in tension face can take no more upcoming loads and transfers it to the concrete section ultimately.

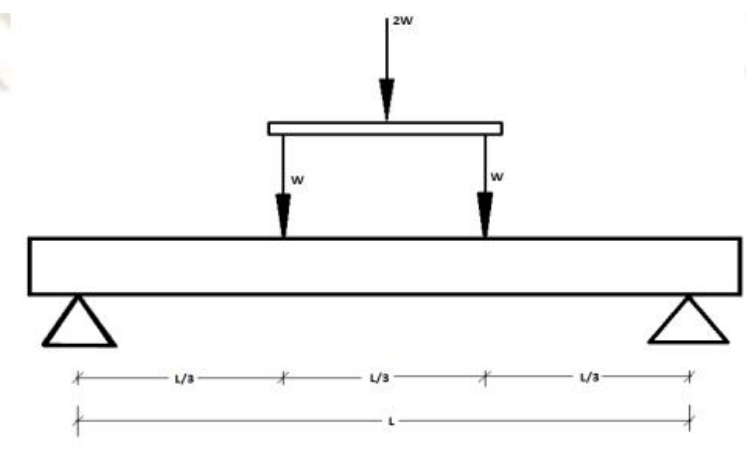

Fig-5: Two point loading system

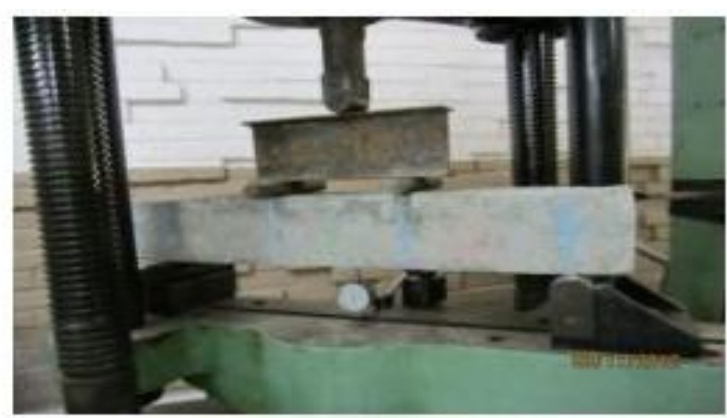

Fig-6: Test Setup to check flexural strength of Beam

\section{EXPERIMENTAL TEST RESULTS}

Table-1: Results

\begin{tabular}{|c|c|c|c|c|c|}
\hline Sr. No. & $\begin{array}{c}\text { Beam } \\
\text { Designation }\end{array}$ & $\begin{array}{l}\text { Cracking Load } \\
\text { in KN }\end{array}$ & $\begin{array}{c}\text { Average } \\
\text { Cracking Load } \\
\text { in KN }\end{array}$ & $\begin{array}{c}\text { Ultimate } \\
\text { failure load in } \\
\text { KN }\end{array}$ & $\begin{array}{l}\text { \% increase } \\
\text { in strength }\end{array}$ \\
\hline 1 & $\mathrm{RCC} 1$ & 49 & \multirow{2}{*}{49.5} & 88 & \multirow{4}{*}{$\begin{array}{c}167.5 \\
\text { (Cracking } \\
\text { Load) }\end{array}$} \\
\hline 2 & RCC 2 & 50 & & 74 & \\
\hline 3 & RCCR 1 & 84 & \multirow{2}{*}{102} & 145 & \\
\hline 4 & RCCR 2 & 120 & & 145 & \\
\hline 5 & WF 1 & 38 & \multirow{2}{*}{41.5} & 75 & \multirow{4}{*}{$\begin{array}{c}110.5 \\
\text { (Cracking } \\
\text { Load) }\end{array}$} \\
\hline 6 & WF 2 & 45 & & 76 & \\
\hline 7 & WFR 1 & 99.5 & \multirow{2}{*}{81.75} & 145 & \\
\hline 8 & WFR 2 & 64 & & 125 & \\
\hline
\end{tabular}




\section{OBSERVATIONS}

\subsection{R.C.C. Under Reinforced Beam}

In RCC beam, as steel is introduced failure was in tension zone that is at the bottom zone. Cracking load was observed to be $49.5 \mathrm{KN}$.

$>\quad$ In RCCR beam, failure was observed in tension zone itself only but observed at the cracking load $102 \mathrm{KN}$. Cracks got widened at a load of $145 \mathrm{KN}$.

\subsection{R.C.C. Beam Weak in Flexure}

$>\quad$ In beam weak in flexure cracking was observed at an average load $41.5 \mathrm{KN}$. Flexural cracks were observed. In WFR, the cracking load of $81.75 \mathrm{KN}$.

$>\quad$ Due to de lamination of FRP, failure sound was observed after the application of cracking load. Later on spelling of concrete also took place at load of 125 $\mathrm{KN}$.

\section{COMPARISON OF RESULTS:}

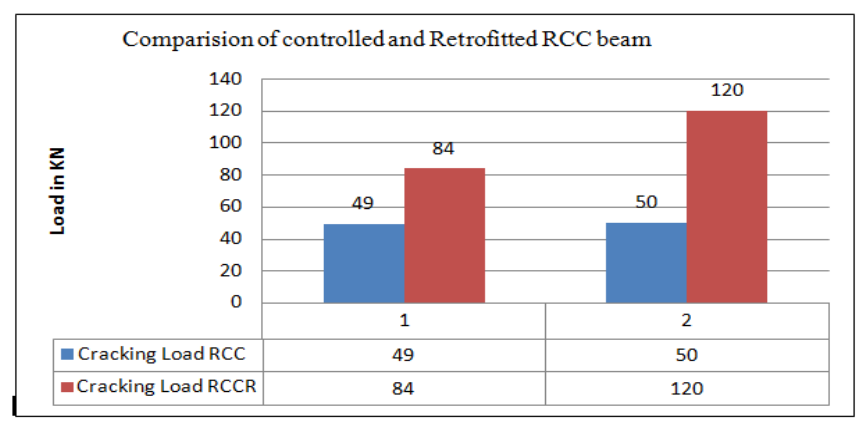

Chart1: Comparision of controlled and Retrofitted RCC beam

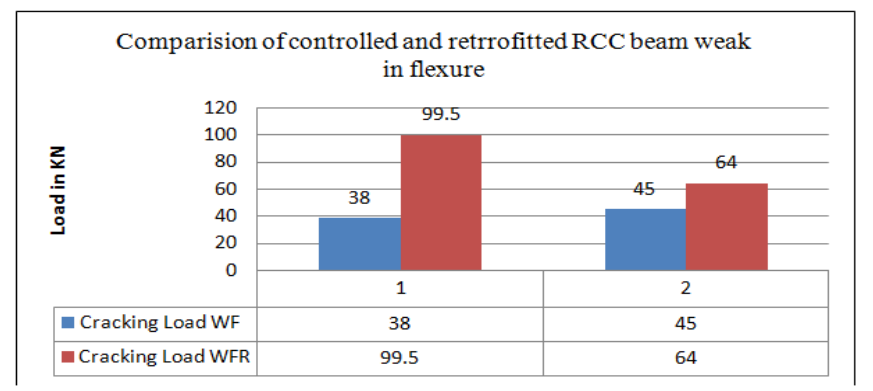

Chart2: Comparision of controlled and Retrofitted RCC beam weak in flexure

\section{CONCLUSIONS}

Based on experimental results following conclusions are drawn

1. Effective procedure of wrapping enhances the strength considerably including the change of failure mode as well as change the location of failure plane.
2. Flexural retrofitting also increases the shear strength of concrete.

3. The beam failure mode was as expected that is beam weak in flexure produced flexural mode of failure and R.C.C. balanced section also exhibited flexural cracks.

\section{REFERENCES}

[1]. Swamy, R. N., Mukhopadhyaya, P., and Lynsdale, C. (1997). "Ductility considerations in using GFRP sheets to strengthen and upgrade structures Non- metallic (FRP) reinforcement for concrete structures, Vol1, Japan Concrete Inst., $637-644$

[2]. Spadea, G., Bencardino, E, and Swamy, R. N. (1997). "Strengthening and upgrading structures with bonded CFRP sheets-design aspectsfor structural integrity." Non-metallic (FRP) reinforcement for concrete structures Vol. I, Japan Concrete Inst., $629-636$

[3] Khalifa, A., W.J. Gold, A. Nanni, and M.I. Abdel Aziz(1998), "Contribution of Externally Bonded FRP to Shear Capacity of Flexural Members" ASCE-Journal of Composites for Construction, Vol. 2, No.4, pp. 195- 203.

[4]. Chaallal O, Shahawy M. (2000) Performance of fiber reinforced polymer wrapped reinforced concrete column under combined axial-flexural loading, ACI Structural Journal, No. 4, 659-69.

[5]. Daft Duthinh and Monica starnes (2001), "Strengthening of Reinforced Concrete Beams with Carbon FRP" National Institute of Standards and Technology, Gaithersburg U.S.A. [6]. Tarek H. Almusallam and Yousef A. Al-Salloum (2005), “ Use of Glass FRP Sheets as External Flexure Reinforcement in RC Beams"

[7]. C. W Lankinen and K. A. Soudki (2008), "Behaviour of rectangular reinforced concrete members confined with GFRP sheets".

[8]. R. Balamuralikrishnan1,* and C. Antony Jeyasehar2 (2009), "Flexural Behavior of RC Beams Strengthened with Carbon Fiber Reinforced Polymer (CFRP) Fabrics" Vol 3, Open civil Engineering Journal.

[9]. Nadeem A. Siddiqui* (2009), “'Experimental investigation of RC beams strengthened with externally bonded FRP composites" Latin American Journal of Solids and Structures 6, 343-362.

[10]. Asst. Prof. Anumol Raju and Asst. Prof .Ligi Anna Methew (2013), "Retrofitting of Rc beam using FRP".

[11]. IS 456:2000, "Indian Standard Plain and Reinforced Concrete - Code of Practice (fourth revision)", Bureau of Indian Standards, July 2000.

[12]. IS10262:1982,'Indian Standard Recommended Guidelines for Concrete Mix Design (fifth revision)" Bureau of Indian Standards, March 1998 